\title{
El cuerpo como apertura a la triada: sexo, género y deseo en algunas prácticas del arte contemporáneo ${ }^{1}$
}

\section{Artículo de reflexión}

\section{David Ramos}

Universidad Pedagógica Nacional, Colombia david.ramos.3@gmail.com

Recibido: 9 de mayo de 2018

Aprobado: 14 de junio de 2018

Cómo citar este artículo: Ramos, David (2019). El cuerpo como apertura a la triada: sexo, género y deseo en algunas prácticas del arte contemporáneo. Calle 14: revista de investigación en el campo del arte 14(25), pp. 114-123. DOI: https://doi.org/10.14483/21450706.14053

1 Este artículo deriva de la ponencia presentada - bajo el mismo título- en el I Encuentro Interdisciplinario de la Escuela de Ciencias Sociales, Artes y Humanidades "El deseo y sus orillas", organizado por la UNAD (Bogotá, Colombia) en noviembre de 2017.

\section{(9) (1)}

https://creativecommons.org/licenses/by/4.0/deed.es

Parquedades, escenas de parque para una actriz, video y música. (1987). Una obra de José Alejandro Restrepo con la participación de María Teresa Hincapié. Cortesía: José Alejandro Restrepo. 

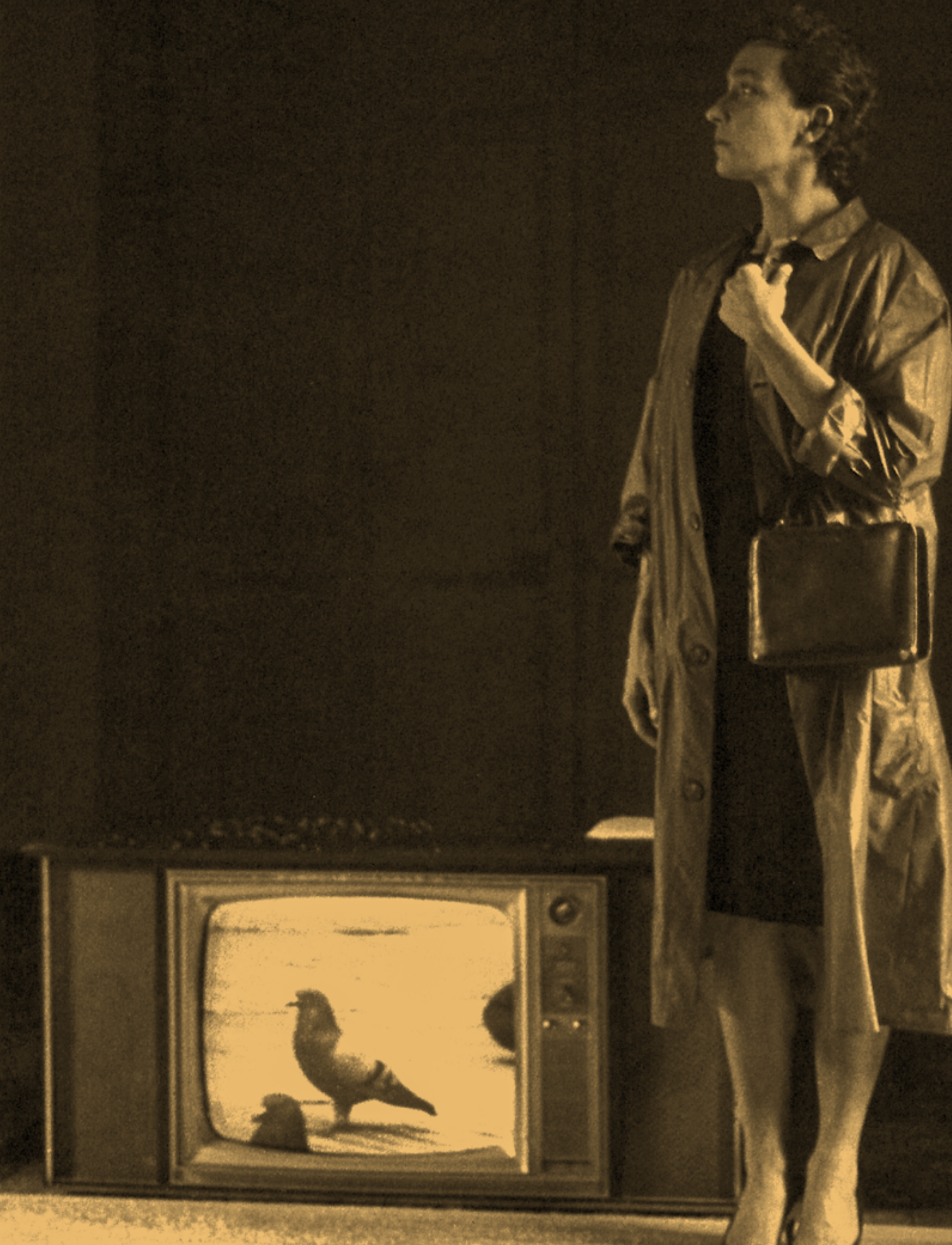
an

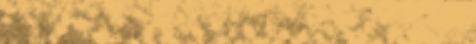

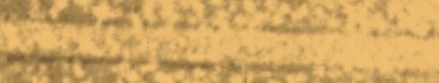
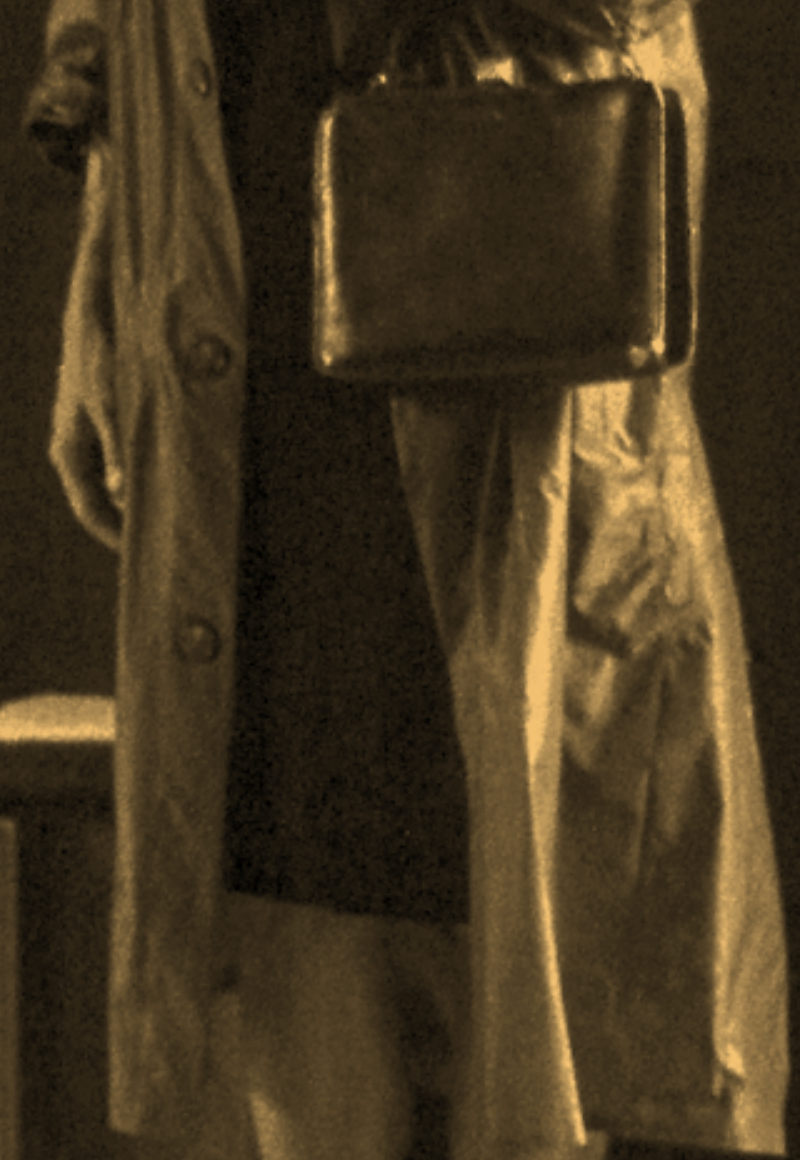
El cuerpo como apertura a la triada sexo, género y deseo en algunas prácticas del arte

contemporáneo

\title{
Resumen
}

A lo largo de este artículo hago una aproximación a un análisis de algunas prácticas artísticas contemporáneas que parten del cuerpo como estrategia reflexiva y dan apertura a otras formas de entender el género, el sexo y el deseo en contraste con una sexualidad hegemónica: la heterosexualidad. Para desarrollar lo anterior, propongo una estructura en tres momentos. Inicialmente, hago un panorama teórico sobre conceptos que considero importante situar desde los estudios de género. En un segundo momento, presento un análisis de algunas obras de cinco artistas (María Teresa Hincapié, Orlan, Piere Moliniere, Catherine Opie y Félix González-Torres) quienes, desde mi perspectiva, se vinculan con unas visuras que amplían la heterosexualidad hegemónica y las construcciones del género y el sexo. Finalmente, enuncio algunas conclusiones preliminares en torno al tema para abrir la discusión sobre las relaciones entre arte, cuerpo y la triada de conceptos desarrollados.

\section{Palabras claves}

Deseo; género; prácticas artísticas contemporáneas; sexo

The body as an opening to the triad sex, gender and desire in some contemporary art practices

\begin{abstract}
Throughout this article I approach and analyze some contemporary artistic practices that depart from the body as a reflexive strategy and open up other ways of understanding gender, sex and desire in contrast to a hegemonic sexuality: heterosexuality. To elaborate on this, I propose a three-part structure. Initially, I make a theoretical overview about concepts that I consider important to contextualize within gender studies. Then, I present an analysis of works by five artists (María Teresa Hincapié, Orlan, Piere Moliniere, Catherine Opie and Félix González-Torres) that, from my perspective, are linked to visions that expand on hegemonic heterosexuality and the constructions of gender and sex. Finally, I enunciate some preliminary conclusions about the topic to open the discussion about the relationships between art, body and the triad of studied concepts.
\end{abstract}

\section{Keywords}

Desire; gender; contemporary artistic practices; sex

\section{Résumé}

Tout au long de cet article, j'aborde et analyse certaines pratiques artistiques contemporaines qui partent du corps en tant que stratégie réflexive et ouvrent d'autres manières de comprendre le genre, le sexe et le désir contrairement à une sexualité hégémonique: I'hétérosexualité. Pour élaborer sur cela, je propose une structure en trois parties. Dans un premier moment, je fais un survol théorique des concepts qu'il me semble important de contextualiser dans les études de genre. Ensuite, je présente une analyse des œuvres de cinq artistes (María Teresa Hincapié, Orlan, Piere Moliniere, Catherine Opie et Félix González-Torres) qui, de mon point de vue, sont liées à des visions qui développent l'hétérosexualité hégémonique et les constructions du genre et le sexe. Enfin, j'énonce quelques conclusions préliminaires sur le sujet pour ouvrir le débat sur les relations entre art, corps et triade de concepts étudiés. 


\section{Mots clés}

Desire; genre; pratiques artistiques contemporaines; sexe

O corpo como uma abertura para a tríade sexo, gênero e desejo em algumas práticas de arte contemporânea

\section{Resumo}

Ao longo deste artigo, abordo e analiso algumas práticas artísticas contemporâneas que partem do corpo como estratégia reflexiva e abrem outras formas de compreender gênero, sexo e desejo em contraste com uma sexualidade hegemônica: a heterossexualidade. Para elaborar isso, proponho uma estrutura de três partes. Inicialmente, faço uma visão teórica sobre conceitos que considero importantes para contextualizar nos estudos de gênero. Em seguida, apresento uma análise das obras de cinco artistas (Maria Teresa Hincapié, Orlan, Pière Moliniere, Catherine Opie e Félix González-Torres) que, a meu ver, estão vinculadas a visões que se expandem sobre a heterossexualidade hegemônica e as construções de gênero e sexo. Finalmente, enuncio algumas conclusões preliminares sobre o tema para abrir a discussão sobre as relações entre arte, corpo e a tríade de conceitos estudados.

\section{Palavras-chaves}

Desejo; gênero; práticas artísticas contemporâneas; sexo

Sug kuirpu kami kimsasina tukungapa: kari u warmi, munai arti sutikarka iachaikungapa kai

\section{Maillallachiska}

Ña kai tsabajukuna ruranimi sug kaiaia kai Nukanchipa kaugsai tiaskapi kalarimi imasami kai kairpi kami kari u warmi; chasaitata imasami kaugsai iukami kari i warmi. Ña kai ikuti rurangapa ninimi imasata rurai kaiaringapa kami kimsa wachuma. Ña kaiaringapa kaura iuiami tiawa imasami Nukanchipa kuirpitu kagta; Ña ikuti parisma kawaspa kawachinimi pichka runakunatpa tsabajukuna kasa sutikuna (Maria Teresa Hincapie, Orland, Piere Moliniere, Catherine Opie y Felix Gonzales-pa. Torres) kai nukapamanda kawaspaka atumi tuku imasa kagta runakunapa kaugai. $\tilde{N} a$ puchukangupa kaura ninimi Nukapa rimaikuna kai artikunamanda kai kuirpukunamanda i kimsa iuiarii kai arti tsabanga.

\section{Rimangapa Ministidukuna}

Munai imasa kagta; imasami kai ruraikuna ka kai punchamandata; kati u warmi 


\section{A propósito de la triada sexo-género-deseo}

Dar definiciones cerradas y determinantes sobre el sexo, el género y el deseo resulta problemático a la hora de comprender las innumerables apuestas teóricas que en las últimas décadas se han dado desde campos de saber como el feminismo, las teorías queer y los estudios de género. Aun así, quiero establecer unos puntos de anclaje que nos sirvan para crear una caracterización de estos términos, centrándome en elaboraciones de Judith Butler ${ }^{1}$ y Óscar Guasch, ${ }^{2}$ los cuales encuentro de gran utilidad para el análisis que planteo más adelante en relación con el trabajo artístico de María Teresa Hincapié, Orlan, Piere Moliniere, Catherine Opie y Félix González-Torres.

Para Butler (2001), la discontinuidad central entre sexo y género se halla en medio de los cuerpos sexuados y los géneros construidos culturalmente, basados ambos en los binarismos hombre/mujer, para el primero, y masculino/femenino, para el segundo. La autora nos presenta al género como una construcción histórica, social y cultural, pues no es el resultado causal del sexo, sino más bien, es una interpretación múltiple de este, que corresponde al significado cultural que nuestro cuerpo sexuado asume $y$, por tanto, se produce performativamente.

Lo que Butler (2002) define como performatividad del género - que tradicionalmente nos ha definido como masculinos para el caso de los hombres y femeninas para el caso de las mujeres - no es un "acto" singular, sino la reiteración de un conjunto de normas reguladoras que materializan el sexo en el cuerpo, es decir la materialización del sexo. Siguiendo a la autora, en estas prácticas reiterativas o rituales, el sexo se naturaliza, pero a la vez abre fisuras que representan inestabilidades en las construcciones de dicho sexo. De ahí que Butler (2001) critique el carácter inmutable del sexo desde una perspectiva naturalista y esencialista, propio de perspectivas como la anatomía, la genética o la biología, pues como constructo cultural, el sexo vendría a ser la materialidad del género. Por ello, el sexo, como una entidad física no dada, lo construimos desde nuestra experiencia a partir del nacimiento, en tanto empezamos a reconocernos como hombres y/o mujeres desde las relaciones establecidas con el género y su performatividad.

\footnotetext{
1 Filósofa y feminista norteamericana.

2 Geógrafo, historiador, antropólogo y docente de la Universidad de Barcelona, España.
}

Hasta aquí he hablado de algunas relaciones entre género y sexo, pero ¿cuáles son sus vínculos con el deseo? Siguiendo a Guasch (2000), el deseo tiene que ver con la necesidad pero, sobre todo, con una correspondencia a todos los estímulos sociales, culturales y biológicos que vehiculan la realización del placer. Para el mismo autor, en tanto es una construcción social, el deseo es generado y modelado por la cultura, por ello es una expresión colectiva que posteriormente tiene lugar en los individuos.

La atracción física y socioafectiva traducida en el deseo sexual, o el deseo erótico como lo enuncia Guasch (2000), hace parte de un proceso de regulación social que tiene en cuenta las particularidades de cada cultura, sociedad o momento histórico. Por ello, y en esto concuerdo con el autor, la sexualidad es una estrategia social que genera y controla el deseo erótico desde la normatización; en este sentido, la sexualidad no es natural y unívoca, más bien es plural y cambiante. Para Guasch (2000), cada sociedad posee unos saberes sexuales hegemónicos que aseguran el orden social para legitimarlo. En nuestra sociedad, la Occidental - cargada de la tradición judeocristiana y patriarcal-, la heterosexualidad corresponde a este saber hegemónico. Paralelamente, existen unos saberes sexuales subalternos que cuestionan y a veces permiten la emergencia de propuestas alternativas a lo hegemónico. En nuestro caso, estaríamos hablando de la homosexualidad o la bisexualidad, por poner un ejemplo.

Resumiendo lo dicho, aquí, podemos decir que, a partir de nuestra experiencia social y personal con el mundo nos identificamos con un sexo (hombre/mujer) más allá de unos determinantes biológicos; construimos nuestro género (femenino y/o masculino) en distintos grados acordes con nuestra crianza, contexto, personalidad, entre otros y poseemos un deseo erótico y afectivo hacia personas del sexo contrario, del mismo sexo o ambos, que definen nuestra orientación sexual. A pesar de las múltiples relaciones que pueden establecerse entre estos tres elementos, podemos asegurar que la heterosexualidad hegemónica ha instituido unas equivalencias deterministas basadas en los binarismos. Así, el hombre debe ser masculino y heterosexual, en contraposición y como su complemento, la mujer debe ser femenina y heterosexual. Aquello que se escapa de esta norma, no es socialmente aceptado y en ocasiones se castiga, como lo homosexual, lo transgénero o lo transexual.

Sin duda, tanto el sexo, como el género y el deseo pasan por la experiencia corporal. El cuerpo, también 
como una construcción sociocultural, nos permite establecer relaciones individuales y colectivas para vivenciar, entre otras cosas, nuestra afectividad, el placer sexual y nuestro lugar como sujetos sexualizados y generizados; esta experiencia está mediada por unas relaciones de poder que regulan los cuerpos. En este sentido, para Butler (2002), el cuerpo es un proceso de materialización que, como ya lo dije, ocurre desde la performatividad del género para encarnar el sexo desde un ideal regulatorio. Estos cuerpos hegemónicos corresponden a unos estándares de belleza, edad, clase, raza, roles sociales y formas "adecuadas" del deseo dentro de la heterosexualidad establecida en nuestro sistema. Lo anterior es lo que Butler (2002) señala como los cuerpos que importan, los cuales se definen desde el contraste con unos seres abyectos, es decir, aquellos cuerpos, o mejor, sujetos que están por fuera de estos cánones legitimados socialmente.

Es a partir de esta noción de la experiencia que pasa por el cuerpo que a continuación presento algunas prácticas artísticas que ponen en tensión y dan apertura, construyen y de-construyen otras formas del sexo, el género, el deseo y la heterosexualidad.

\section{El arte contemporáneo como apertura}

Podría decirse que las apuestas de artistas que dan cabida a otras reflexiones y críticas alrededor de las construcciones sobre la triada sexo-género-deseo, no son nuevas para el campo del arte. En el contexto de los años sesenta del siglo pasado, la institución y las prácticas artísticas sufrieron un cambio radical en relación con el arte que se venía produciendo, heredado de los últimos siglos, especialmente del XIX, momento en que aparece la figura del "genio creador" y la autonomía del arte en tanto tal.

Como consecuencia a la crítica de la figura de este genio, a la obra como un objeto material único e irrepetible, al museo como espacio legítimo de circulación y a los y las espectadoras como receptores que, desde la observación, solo podían contemplar un determinado producto artístico, el arte clásico entró en crisis. Sumado a ello, el contexto social y político de la época también influenció estas rupturas, por ejemplo la Guerra de Vietnam, Mayo del 68, las luchas por los derechos civiles, los movimientos estudiantiles, activistas y ecologistas, el feminismo, la liberación sexual, el hipismo y demás hechos asociados con la Contracultura en Estados Unidos y Europa. ${ }^{3}$

Es así como algunas prácticas del arte, a partir de los 70 -incluso un antes - hasta la actualidad, empiezan a apropiarse de nuevos modos de producción que expanden las artes plásticas tradicionales (dibujo, pintura y escultura) a lenguajes como la fotografía, el video, la instalación, acciones pensadas desde el cuerpo, entre otros. Así mismo, el arte se ocupa de temas más cercanos a situaciones y contextos "reales" para denunciar o dar cuenta de problemáticas como la desigualad, la exclusión, la inconformidad con la guerra, los distintos tipos de violencias, entre otros. ${ }^{4}$ Esta ampliación nos muestra al o la artista, a los y las espectadoras, pero también al museo y la obra, desde lugares que, como veremos en los trabajos artísticos que voy a citar, escapan de lo que tradicionalmente sería el "Arte".

De esta manera, quiero iniciar presentando la obra de la artista colombiana María Teresa Hincapié “Una cosa es una Cosa" (1990-2005) en la que usa objetos cotidianos y comunes como ropa, cosméticos, artículos de oficina, de cocina y del hogar. Su performance se basa en ubicar cuidadosamente sobre el suelo cada uno de estos objetos íntimos dentro de una fila para darles un lugar. La artista dispone cada cosa dentro del recorrido de un dibujo que tiene forma de una espiral cuadrada. Los objetos inician guardados en cajas de cartón o bolsas de papel que, a lo largo de la acción, son desempacados, organizados y vueltos a empacar.

La reflexión inicial que nos señala Hincapié tiene que ver con los movimientos y acciones domésticas y de nuestra cotidianidad, de allí mi interés por esta obra en tanto parte del cuerpo como punto reflexivo en torno a la construcción del género, el femenino en este caso. Poniendo en escena objetos y acciones relacionadas con los roles de la mujer en la sociedad (madre, esposa, cuidadora, oficinista, entre otras.), y acciones tradicionalmente vinculadas a la feminidad (cocinar, maquillarse, hacer el mercado, entre otras.), la artista parte

\footnotetext{
3 No hay que olvidar aquí el contexto político latinoamericano, sobre todo en décadas posteriores (sesenta y ochenta) en relación con las dictaduras militares, el retorno a la democracia y, en nuestro caso, el conflicto armado colombiano, pero también todos los procesos de crítica vinculados con la tensión centro-periferia y las desigualdades de clase, género y raza.

4 Recordemos a Paul Ardenne (2006) cuando habla del "arte contextual".
} 
de la intimidad para trasladarla a la esfera de lo público desde su acción y, de manera sutil, poner en evidencia el género y sus implicaciones sociales desde prácticas cotidianas que normalmente pasamos por alto.

La siguiente artista que refiero es la francesa Orlan, nombre que adopta en los años sesenta para proclamarse como "Santa Orlan". Gran parte de su obra critica al catolicismo y las concepciones que la religión tiene del cuerpo, el placer, el dolor y la imagen del mártir y la autoflagelación. Orlan concibe su cuerpo como una obra, pues es un soporte que puede ser transformado a su antojo. Es así como propone un "Arte Carnal" que, a modo de autorretrato, usa la tecnología y los descubrimientos científicos para su realización. A partir de la desfiguración y refiguración de la carne, del cuerpo, Orlan rechaza el dolor como redención o purificación.

Entre 1990 y 1993, realiza sobre sí misma nueve cirugías estéticas para modificar su físico; en algunos casos, acude a psicoanalistas para alterar su personalidad. Con las operaciones interviene su cara para cambiarla, incorporando rasgos faciales de íconos de belleza de la historia del arte, entre ellos el rostro de la Mona Lisa, el mentón de la Venus de Botticelli, los labios de la Europa de Boucher, los ojos de la Diana, entre otros. Usando anestesia local para evitar el dolor, Orlan permanece consciente durante los procedimientos, pudiendo leer una serie de textos de varios autores reconocidos en torno al cuerpo y la identidad. En su séptima cirugía titulada "Omnipresencia" (1993) transmite en vivo y en directo la acción desde el quirófano en Nueva York a galerías y museos de otras ciudades de Europa y América. El público podía establecer comunicación con la artista a través del envío de mensajes con sus percepciones vía Internet o Fax, así mismo, tenía la posibilidad de conversar, en tiempo real, con ella durante la intervención quirúrgica.

La obra de Orlan cuestiona diversos elementos en torno al cuerpo como mediador y contenedor del sexo, el género y el deseo desde la reconfiguración de su aspecto. Esto nos lo presenta a partir de la crítica al ideal de belleza clásico occidental que impone un tipo de feminidad (mujer delgada, de facciones delicadas, blanca, rubia, pura, gentil, entre otros.), que se instala en el cuerpo e instaura una manera particular de desear ese cuerpo por parte de un género contrario y complementario: un hombre masculino. Su crítica ocurre cuando cuestiona los límites del sexo desde las intervenciones a su cuerpo, tensionando su aparente naturalidad y rompiendo las dicotomías hombre/mujer.
Para Orlan, su obra hace referencia a una identidad que no es definida y definitiva, por el contrario, es nómada, múltiple y móvil, por tanto las categorías de "hombre" y "mujer" son inacabadas y cambiantes. Es clave cuando la artista convierte su acción en participativa e interactiva. Involucrando a los y las espectadoras, cuestiona el lugar del público como un sujeto que contempla una obra para, esta vez, hacerlo parte del proceso de creación (la cirugía en este caso). Esta participación también traslada, con mucha más contundencia, a la esfera de lo público el cuerpo de la artista y su modificación.

Otro ejemplo que nos permite ampliar los límites del cuerpo y sus formas de experimentarlo, lo podemos analizar en la producción fotográfica del francés abiertamente homosexual y travesti, Pierre Moliniere, en la década de los sesenta y parte de los setenta. A través del retrato y del fotomontaje análogo, nos muestra unos cuerpos travestidos que aparecen como seres andróginos que vivencian el placer y el deseo erótico por fuera de la norma.

A partir del uso del collage que hace Moliniere podemos crear un símil con el cuerpo, el cual se construye desde fragmentos y por tanto lo podríamos entender como una entidad modificable al antojo del sujeto que lo porta. Los cuerpos masculinos y femeninos que se modifican y se fragmentan, vuelven a reconstruirse a partir del fotomontaje y están ante nosotros desde lo serial, lo reiterativo y lo reinterpreativo.

En muchas de sus imágenes, especialmente en sus autorretratos, el fotógrafo cuestiona las divisiones entre la feminidad y la masculinidad, dando lugar a lo transgénero, lo transexual y la androginia como posibilidades para una serie de cuerpos plurales de hombres y de mujeres que, por medio del cuerpo travestido trasgreden las normas sociales que regulan el género desde los comportamientos, las formas de vestir, los roles o las prácticas sexuales.

Los cuerpos que Moliniere captura nos sacan del lugar común del retrato y el sujeto posante en la práctica fotográfica, es decir, un sujeto que normalmente está con su cuerpo vestido, esconde ciertas partes desde lo socialmente aceptado y ratifica tabús en torno a las prácticas sexuales. En reacción a esto, Moliniere nos confronta como observadores ante sus imágenes, cuestionándonos sobre la heterosexualidad hegemónica. Esta confrontación también ocurre en torno al deseo erótico y la sexualidad, pues el fotógrafo subvierte la sexualidad regulada y visibiliza el tabú de 
la masturbación y otras prácticas sexuales como las homosexuales y el sadomasoquismo. Sus imágenes nos llevan a pensar en otras formas de experimentar el placer por fuera de lo establecido.

El cuerpo capturado en imagen por Moliniere, o mejor, eternizado en una fotografía que permanece inmóvil ante nosotros, pasa del ámbito de lo privado (donde normalmente se encuentra la desnudes, las prácticas sexuales, incluso la homosexualidad) para visibilizarse en lo público, lo externo y lo colectivo. No hay que olvidar el contexto donde esto ocurre: años sesenta y las rupturas con la cultura hegemónica, entre ellas la liberación sexual y la redefinición de la homosexualidad como una enfermedad mental.

Desde una perspectiva similar haciendo uso de la fotografía, la artista Caterine Opie realiza una serie de imágenes que retratan personas, que, a través de sus cuerpos y la manera de vivenciarlos, trasgreden nociones tradicionales del sexo, el género y el deseo. En sus series fotográficas, Opie nos habla de las comunidades queer de Los Ángeles y San Francisco en Estados Unidos, refiriéndose directamente a los procesos de construcción de las identidades culturales y sexuales, las cuales, según Opie, se producen en relación con lo comunitario y el contexto próximo.

Particularmente en la serie "Ser y Tener" (1991) la artista hace una reflexión sobre la masculinidad, más allá de un cuerpo que posee un determinado sexo, mientras que en "Retratos" (1993-1997) hace énfasis en la diversidad de la comunidad queer, sus cuerpos y formas de construir el género desde el travestismo, la transexualidad y lo transgénero. Así, sus fotos nos permiten reconocer los límites del género al lado de las nociones de edad o raza. La artista también visibiliza la homosexualidad, la presencia de unos cuerpos andróginos que cotidianamente están ocultos y la situación de la comunidad queer que es silenciada por las normas sociales. Sus imágenes logran romper con estereotipos sobre la homosexualidad, donde un hombre gay debe feminizarse y, en oposición, una mujer lesbiana debe masculinizarse.

El discurso de Opie, emerge de su identidad como lesbiana. Algunos de sus autorretratos nos pueden resultar interesantes en este sentido, en tanto son de orden autobiográfico, confesional y doméstico. Por ejemplo, en «Autorretrato / Corte» (1993) la artista reflexiona sobre la vulnerabilidad física de los actos sadomasoquistas $y$, en paralelo, cuestiona el ideal de familia tradicional y nuclear, dando paso a su posición como lesbiana. Opie usa su cuerpo como soporte desde el acto de dibujar con una cuchilla una imagen que pareciera ser hecha por un niño; esto lo hace sobre la piel de su espalda y sin mostrar su rosto, para, finalmente, retratarse. De esta manera, Opie aparece retratada a través de lo paradójico y contradictorio, dejándonos ver su condición e identidad como lesbiana entre lo visto y lo oculto y lo aceptado e in-aceptado.

Otro de sus autorretratos es "Lactancia" (2004). En esta fotografía sostiene a su hijo para amamantarlo, tal como en las imágenes clásicas del arte occidental. Además de cuestionar estas formas de representación, podemos decir que Opie critica y subvierte los roles femeninos sobre la maternidad, el deber ser mujer y el prototipo de belleza y feminidad. Esto lo hace mediante su cuerpo que está desnudo y posa ante la cámara para hablar de un cuerpo masculinizado (grande, fuerte, tosco, de cabello corto) que amamanta a su hijo varón, al cual ve conmovedoramente, tal y como se muestra a la Virgen María en varios cuadros clásicos.

Sin duda, el trabajo de Opie vincula lo individualcolectivo y lo privado-público mediante la presentación de unos cuerpos diversos que son capturados en imagen. La artista nos pone ante unas maneras de mostrar al otro y a la otra, en función del acto de mostrarse y exponerse a sí misma desde la fotografía.

Para finalizar, quiero referirme a la obra del cubano Félix González-Torres, la cual tiene relación con Opie, sobre todo en la apertura a reflexiones sobre la homosexualidad, esta vez tomando como base la afectividad hacia una persona del mismo sexo en la creación de metáforas sobre el amor, la soledad, el duelo y la ausencia. En los años noventa González-Torres pierde a Ross, su pareja con la cual convivió por más de ocho años y quien padecía de SIDA. Durante el año de su muerte en 1991, el artista realiza una serie de obras, instalaciones en su mayoría, con las cuales buscaba elaborar el duelo y rendir un homenaje a Ross.

En "Sin título - Amantes perfectos" coloca dos relojes de cocina sincronizados a la misma hora, que con el paso del tiempo iban perdiendo sincronía, distanciándose poco a poco hasta que uno de los dos se detenía. La obra puede leerse como una metáfora del amor y la muerte de Ross. Otra de sus obras es "Sin título Cama". El artista instala 24 avisos (día de la muerte de su pareja) en distintos puntos de Nueva York con una fotografía que mostraba las huellas de dos cuerpos 
sobre almohadas y sábanas de una cama. La obra pone de manifiesto un acto íntimo que se hace público al exponerse masivamente en las vallas; así mismo, nos enfrenta con la paradoja de una ausencia que a su vez está presente, tal vez como Ross y su cuerpo.

Quizá una de las obras más interesantes de GonzálezTorres es "Sin título - Retrato de Ross en Los Ángeles". En el espacio de exposición se encuentra una montaña de caramelos envueltos en papeles de distintos colores que pesan en total 175 libras, equivalencia a la masa corporal de Ross. La obra se completa cuando los y las espectadoras toman los dulces y los llevan consigo, disminuyendo el tamaño de la pila, tal como ocurrió con el cuerpo de Ross consumido por la enfermedad hasta su muerte. A través de la presencia del cuerpo metaforizado en los dulces, el artista propone un duelo que se vuelve colectivo con la participación del público y su presencia, la cual se tensiona con la ausencia de Ross.

A diferencia de las obras que he presentado hasta el momento, las apuestas de González-Torres no muestran al cuerpo en sentido literal como lo hace Opie o Molinere, ni lo emplea como medio o lenguaje como en el caso de Orlan o Hincapié. González-Torres lo metaforiza para remitirnos a la presencia del cuerpo, un cuerpo del otro. Estas metáforas también aluden al amor entre dos personas del mismo sexo, expandiendo la homosexualidad más allá del deseo erótico para situarlo en la afectividad. Esta expansión inserta en sus metáforas también nos habla de la complementariedad, no desde los binarismos entre opuestos (hombre-mujer, femenino-masculino) sino desde la referencia a lo igual: dos relojes, dos almohadas, los caramelos.

\section{A modo de conclusión}

A manera de cierre, quiero referir algunos elementos que me parece importante señalar. En primera instancia, resalto la relación del cuerpo con el arte contemporáneo como posibilidad para dar aperturas en la triada: sexo, género y deseo. Su uso como medio y lenguaje, como presentación y representación o como metáfora, nos hace pensar lo corporal más allá de una entidad dada, material, estable y funcional. Las apuestas creativas que se hacen en y sobre el cuerpo son reflejo de lo social que vivenciamos de forma individual. De ahí que el cuerpo aparezca como una estrategia para reafirmar, debatir o explorar nuevas relaciones con lo impuesto y socialmente aceptado.
Siguiendo a Judith Butler, esto sería la relación entre unos cuerpos que importan - aceptados y constituidos desde las normas - y la emergencia de seres abyectos como posibilidad para preformar el género y materializar el sexo desde otros lugares. Esto mismo tiene que ver con la construcción de nuestra sexualidad que pasa por el cuerpo, no solo desde el deseo erótico sino también por el afectivo, el cual puede vivenciarse o expresarse dentro o fuera de la heterosexualidad.

Las prácticas del arte contemporáneo crean visuras con lo establecido, aperturas que problematizan la heterosexualidad, pero sin la pretensión de excluirla. El arte abre nuevas maneras de construir la feminidad, la masculinidad, el hecho de "hacerse hombre" o "hacerse mujer"; nos permite visibilizar y fabricar visuras del género, visuras del sexo y visuras del deseo. Esto no es otra cosa que comprender nuestra posición como sujetos, al margen o dentro de lo instituido, en una sociedad como la nuestra: compleja, múltiple e inacabada, bombardeada por los medios de comunicación, excluyente y, en algunos casos, poco reflexiva sobre la herencia de la cultura hegemónica occidental.

Construir esta mirada abierta y crítica no es más que hablar del arte como una posición y un acto político frente al mundo. En este contexto, la política, siguiendo a Jacques Rancière (2006), tendría que ver con la ruptura en la configuración de unas divisiones sensibles establecidas a través de una serie de actos (artísticos en este caso) que representan el espacio de partes definidas, mostrando la ausencia de otras partes silenciadas (como aquellas construcciones en torno al sexo, al género y al deseo que escapan de lo establecido). De ahí que la política haga escuchar discursos que antes eran ruidos $y$, por tanto, sea el encuentro de procesos heterogéneos entre la policía ${ }^{5}$ y la igualdad, esta última es puesta en juego desde prácticas u operaciones disensuales que apuntan a la emancipación (Rancière, 2006). Por ello, la esencia de la política es el disenso puesto en marcha por actores concretos o sujetos políticos que se distinguen con realidades de grupos de identidades sociales específicas.

\footnotetext{
5 La policía hace referencia a la ley implícita, al reparto de lo sensible, es decir, la ley implícita que define el mundo para separar y excluir, para también para hacer participar. La policía se refiere al gobierno que organiza la comunidad y su consentimiento, es una construcción simbólica de lo social que jerarquiza lugares y funciones, es un orden de los cuerpos que delimita modos de hacer, ser y decir, por tanto correspondiente a lo visible y lo decible, definiendo lo oculto y lo no dicho: el ruido (Rancière, 2005, 2006).
} 
Estos disensos con lo establecido, tiene mucho que ver con lo que he expuesto hasta aquí en relación con esas aperturas y visuras en relación a las construcciones del sexo, el género, el deseo, la sexualidad, incluso el cuerpo, desde y en las prácticas del arte contemporáneo. Desde la perspectiva de Rancière, esto no es más que una política de la estética referida a "la manera en que las prácticas y las formas de visibilidad del arte intervienen en la división de lo sensible y en su reconfiguración, en el que recortan espacios y tiempos, sujetos y objetos, lo común y lo particular" (Rancière, 2005, p. 15).

\section{Referencias}

Ardenne, P. (2006). Un Arte Contextual: Creación artística en medio urbano, en situación, de participación. Murcia: Centro de documentación y estudios avanzados de arte contemporáneo.

Butler, J. (2001). El género en disputa: el feminismo y la subversión de la identidad. México D.F.: Paidós.

(2002). Cuerpos que importan. Sobre los límites materiales y discursivos del sexo. Barcelona: Paidós.

Guasch, O. (2000). La crisis de la heterosexualidad.

Barcelona: Editorial Laertes.

Rancière, J. (2005). Sobre políticas estéticas.

Barcelona: Museud'Art Contemporani de Barcelona.

(2006). Política, policía, democracia. Santiago

de Chile: Lom Ediciones. 